\title{
AXL Receptor Tyrosine Kinase/cMET Inhibitor BPI-9016M
}

National Cancer Institute

\section{Source}

National Cancer Institute. AXL Receptor Tyrosine Kinase/CMET Inhibitor BPI-9016M. NCI

Thesaurus. Code C132025.

An orally available inhibitor of the AXL receptor tyrosine kinase ( $A X L ; U F O)$ and the receptor tyrosine kinase c-Met/hepatocyte growth factor receptor (HGFR) with antineoplastic activity. Upon administration, AXL receptor tyrosine kinase/cMET inhibitor BPI-9016M, binds to both AXL and cMet, thereby disrupting both AXL- and c-Metmediated signaling pathways. Altogether, this agent inhibits growth in AXL and cMetoverexpressing tumor cells. AXL, a member of the TAM (TYRO3, AXL and MER) family of receptor tyrosine kinases, and cMet, both overexpressed by many tumor cell types, play key roles in tumor cell proliferation, survival, invasion and metastasis. 